\title{
The International Foundation Year and first year transition: building capital, evolving habitus, developing belonging, preparing for success
}

This article focuses on research that provides new insights into international undergraduates' transition experiences in UK higher education. The study explored ways in which combined experiences of university learning, teaching and support and International Foundation Year $^{1}$ (IFY) attendance at a pathway international college influence first year international students' transition. A mixed-methods research approach included in-depth interviews and a survey that compared groups including previous IFY and non-IFY students and pre and post 1992 UK universities. The Bourdieusian constructs of 'capital' and 'habitus' are presented as a theoretical lens that highlights ways in which attending an IFY helps first year international undergraduates to develop belonging, resilience, student identity, academic confidence and success.

Key Words: International Foundation Year, first year transition, habitus, belonging, capital

\section{Introduction}

This article presents and discusses findings from recent research into first-year international undergraduate students' transition that was funded by This study aimed to identify ways in which international undergraduates' transition experiences are influenced by university pedagogy and support practices, and previous experiences of attending an IFY at an international pathway college. The research also explored ways in which students'

\footnotetext{
${ }^{1}$ International Foundation Year is a generic name for a one-year foundation course at a pathway college, which prepares international students for the first year of their undergraduate degrees. This may be referred to differently in different pathway colleges.
} 
experiences varied depending on whether they did, or did not, attend an International Foundation Year (IFY) in different UK universities and disciplinary contexts. Our findings highlight how students address transition challenges and develop belonging, confidence, resilience and student identity over time, linked to success, which may help inform university and partner college policies and practices both in the UK and internationally. In this context, the IFY is arguably part of the beginning of international students' transition into UK HE, where students have the opportunity to learn about the cultural, social and academic codes and practices necessary when they start university. According to Bourdieu such experiences would enable students to develop the necessary capital and habitus to belong and be successful in HE (Bourdieu, 1988). In relation to undergraduate student transition, Thomas $(2015,41)$ discusses a Bourdieusian analysis, which theorises belonging as 'a relational concept, as a practice and a product of the relations of power embedded in the field of HE, constructed around the privileged identities of student: young and fulltime'. In our research, we argue that this notion of privileged identity may also include home students. However, belonging in UK HE can be problematic for some international students who may not feel they identify with this privileged identity because UK universities are constructed in ways that favour knowledge and experience from dominant groups to the detriment of other groups (Thomas, 2002; Scanlon et al., 2007; Leese, 2010; Gale and Parker, 2014; Pitman and Vidovitch, 2013). This study contributes knowledge to research into international undergraduate students' transition.

The background to this study will now be discussed, followed by an explanation of ways in which the concepts of 'capital' and 'habitus' underpin our research. The methodology and findings sections will then be presented, and finally, the broader research implications will be explored, followed by our conclusion. This research is supported by earlier work (Thomas, 2002; Scanlon et al., 2007; Leese, 2010; Pitman and Vidovitch, 2013; 
Gale and Parker, 2014) in highlighting how developing cultural, linguistic, social and academic capital are important for students acquiring institutional habitus linked to belonging, confidence and success.

\section{Background}

Enhancing first-year undergraduates' experiences is a recent priority for UK and international higher education (HE) (HEA, 2008, Thomas, 2012). Within this context, a concern for UK and international universities has been to enhance international student engagement in learning and teaching (Bartram, 2008; Quan, Smailes and Fraser, 2012). New students may experience a loss of belonging and identity when moving to a new institution, affecting their confidence and engagement (Thomas, 2002: Bourdieu and Passeron, 1977; Scanlon et al., 2007; Leese, 2010). Scanlon et al. (2007) describe how students who leave one institution, such as a college, and enter a new one, such as a university, must construct a new identity, which is challenging. We might understand this as a loss of habitus and the need to develop a new institutional habitus (Thomas, 2002: Bourdieu and Passeron, 1977; Leese, 2010). Scanlon et al. $(2007,228)$ explain that this transition relates to 'loss not only from social contacts but also from loss of place'.

Most students may find transition to HE difficult, but some international undergraduates may find new educational experiences in English speaking universities particularly challenging (Lee, 2010). Griffiths et al. suggest that some international students find adjusting to English speaking HE stressful, and describe this as 'learning shock' or 'academic culture shock' resulting in students' low self-esteem and thoughts of leaving their course $(2005,1)$. The authors $(2016)$ argue that undergraduate students' strong sense of belonging is crucial in enhancing their engagement and success when starting their degrees. 
Hence, UK universities need to ensure that international students belong and are engaged in study when they begin university courses (Back et al., 2012; Morgan, 2016; Morris et al., 2016).

To support international undergraduates' transition into HE, many UK and overseas universities now work in partnership with private sector 'Pathway' colleges such as Kaplan, Study Group, INTO, Cambridge Education Group or NAVITAS (Leech et al., 2016). Such partnerships are a $21^{\text {st }}$ century HE innovation in the UK, US and Australia, the first Kaplan International Pathways college being established in 2005 at Nottingham Trent University (.... (.....), 2018). There are now more than 15,000 students studying with the four largest private pathway providers in the UK annually (Matthews, 2014). Pathway colleges are profit-making organisations whose income derives from student fees, government-sponsored students, agents and universities who pay for every student that successfully progresses into their institution (...., 2018). In the UK, most international students studying at pathway colleges are non-European Union, and come predominately from China, Hong Kong, the Middle East, and Africa. Leech et al. $(2016,34)$ suggest two main reasons why international students attend UK pathway colleges. Firstly, 'their own education system is deemed incompatible with the UK system - only 12 years instead of 13 years - International Foundation Programmes, including IFYs, then are generally designed to fill the gap between an applicant's current level of qualifications and those needed to enter a Bachelor's degree at a UK (or other EU) institution'(Leech et al., 2016, 35). Secondly, pathway colleges enable students to achieve their required English proficiency level of at least ' 5.5 on the International English Language Testing System (IELTS) (Leech et al., 2016, 35)’.

However, international undergraduates also experience transition challenges after studying in pathway colleges. Scanlon et al. discuss misconceptions that contemporary first year students can experience a smooth transition in UK HE even though they have attended 
foundation courses and that 'these proved not to provide students with sufficient...cultural capital to negotiate the first year experience' $(2007,237)$. A key challenge for international students is that they may not mix with home students during the IFY, and struggle to do so once at university as their friendship groups have already been formed. McNorton and Cadinot $(2012,6)$ raise the question of whether 'same nationality support groups' should be encouraged or discouraged during the IFY. Such groups may not encourage integration with UK students, which will be necessary when international students actually start their degrees, and may delay students' progress in English fluency. Earlier research highlighted another key transition challenge that international students who had previously attended an IFY faced, which was their new experience of studying independently in larger groups at university where they received less attention from academic staff in comparison to smaller groups and more attention from staff during the IFY at the pathway college (Authors, 2015). Hence, there is a tension between the pathway college offering a supportive environment which the student needs and, importantly, is paying for, and the college's stated aim of preparing students for the independent study at university.

Nevertheless, there are several advantages for international students who choose to study at pathway international college prior to university, rather than choosing to attend UK sixth form colleges or language schools. Significantly, embedded pathway colleges are physically part of universities, sharing infrastructural links, which other providers cannot offer to the same extent (Authors, 2015; ..., 2018). This can help students acclimatise to university and university staff can meet students getting to know them earlier than direct entry international students (Authors., 2015). In some respects IFYs at pathway colleges provide a generic pedagogic experience for students helping to prepare them for an autonomous HE experience. However, pathway colleges teach varied academic subjects including Art and Design, Science, Business and Engineering sharing university facilities; 
and module content and exam material are aligned to partner university degree subjects (... (...), 2013). In IFYs students learn subject-specific knowledge and skills including research, academic writing and exam preparation that may be challenging for international undergraduates (HEA, 2008; Authors, 2012; .., 2013). In this context, in IFYs at pathway colleges there are opportunities for students to engage in-depth with specific aspects of knowledge construction that takes into account the socio-cultural basis of UK university academic practice. Some universities also provide Peer Assisted Study Support (PASS) sessions at the Pathway College. PASS sessions create opportunities for students to make friends and know what to expect in different disciplines, enabling international students to integrate and engage with study at university (Authors, 2012). Pathway colleges offer a supportive environment through small classes and offer tutorials. A recent monitoring report by QAA of the .... International College at .... (2013) confirmed that students had positive experiences of one to one tutorials and feedback described as "timely and helpful" (QAA, 2013, 2). IFY regular student-led one to one tutorials with academic staff that provide regular timely feedback may help to increase student engagement during the IFY and when starting their degrees (McNorton and Cadinot, 2012). This is also supported by Gu et al. (2009) who found that strong working relationships with teaching staff are crucial in supporting international students' smooth transition during their first year at university. Finally, an IFY may provide international students with sufficient time to adjust to HE academic expectations and culture in UK or other overseas universities (Griffiths et al., 2005; Andrade, 2006; Kingston and Forland, 2008; Authors, 2012). During this time, students establish friendships and working relationships with peers that will continue into their first year at university. Establishing social bonds in personal and academic life when starting a degree, e.g. through Communities of Practice, are described as important in students developing belonging, resilience and identity over time, increasing engagement, confidence and success (Wenger, 
2009; Thomas, 2012; Authors, 2016).

Hence, in theory, the International Foundation Year (IFY) can help international undergraduate students develop belonging and identity to prepare to start university, build resilience and overcome any challenges they may face, contributing to their academic confidence and success. An earlier study at a post-1992 UK university suggests that the IFY helps support students' first year transition in practical terms and enhances their confidence to become independent learners at university (Authors, 2015). However, the authors (2015) also support McNorton and Cadinot's (2012) suggestion that universities and partner colleges must work in close partnership in order to support international students more effectively to start their degrees. Research by Briggs et al. (2012) demonstrates how combined academic and support practices provided by colleges prior to university and by universities when students start university help to enhance student belonging, engagement, identity development, confidence and success.

\section{Conceptualising first year international student transition: capital and habitus}

Student transition may be defined as 'the change navigated by students in their movement within and through formal education' (Gale and Parker, 2014, 734). In this article, our research findings are underpinned by Bourdieu's constructs of 'habitus' and 'capital' as a lens through which international undergraduate student transition can be conceptualised (Bourdieu, 2002; Thomas, 2002; Scanlon et al., 2007; Pitman and Vidovitch, 2013).

Supported by earlier research, in this study, cultural and social capital relate to the importance of communication, friendship and working relationships in international students' development of belonging and institutional habitus (Leese, 2010; Pitman and Vidovitch, 2013; Gale and Parker, 2014; Hurst, 2015). Academic and linguistic capital are concerned 
with such students' knowledge acquisition and their development of academic and linguistic confidence and success (Leese, 2010; Pitman and Vidovitch, 2013; Gale and Parker, 2014; Hurst, 2015). In HE contexts, we follow Thomas' explanation of institutional habitus as 'a set of dispositions created and shaped by the interaction between objective structures and personal histories' (Thomas, 2002, 430: Bourdieu and Passeron, 1977). Pitman and Vidovitch describe this process in relation to capital as 'both the tangible (e.g. money) and intangible (e.g. status) elements that allow some agents within the field to dominate others' $(2013,502)$. According to this conceptual argument, it is important for undergraduate students to develop institutional habitus when starting university, in order to be socially and academically successful, which is linked to the concepts of social, cultural and academic capital. Conversely, as Leese and Pitman and Vidovitch discuss, if students do not develop institutional habitus they may become demotivated (2010; 2013).

To support students through transition, as Scanlon et al. (2007) and Gale and Parker (2014) argue, developing cultural, social and academic capital is crucial for students to develop institutional habitus, and hence, belonging. Leese (2010) and Hurst (2015) also discuss how students' development of linguistic capital is essential for their increasing confidence and success when starting HE. For instance, Hurst $(2015,80)$ suggests that 'linguistic capital is measured in the ability of a student to function in the academic literacy domains...their ability to read and write in academic genres ..., to manage information, operate with digital technologies, understand and represent numerical information and engage with disciplinary discourses'.

According to Thomas (2002), Leese (2010) and Pitman and Vidovitch (2013), developing institutional habitus is an evolving process that can enable undergraduates to overcome challenges during their first year transition, which is linked to their strengthened resilience, belonging and student identity. This process is also argued to relate to students' 
acquisition of increased cultural, social and academic confidence and success when starting HE, which are key elements of cultural, social and academic capital (Thomas, 2002: Bourdieu and Passeron, 1977; Leese, 2010; Pitman and Vidovitch, 2013).

However, as Thomas argues, it may be unrealistic to expect undergraduate first year student transition to be a smooth process (2002). Leese (2010, 243), for instance, discusses how transition challenges can be worsened if students' 'socio-cultural, linguistic and economical capital does not fit with the dominant discourse within the university'. At the beginning of this article we discussed how some international students may not feel they identify with the privileged and dominant undergraduate student identity in UK HE. This is because UK university cultures and processes may favour cultural, social and academic capital that dominant groups have already acquired, disadvantaging less dominant or minority groups (Thomas, 2002; Scanlon et al., 2007; Leese, 2010; Gale and Parker, 2014; Pitman and Vidovitch, 2013). International student transition challenges in UK HE may also be contextualised within the wider UK socio-political climate of change where frequent media reference to immigration may influence students' feelings of belonging in HE and wider UK society.

In this article, the concepts of capital and habitus help to highlight issues relating to international students' integration and success in HE. However, as Green (2013) discusses, Bourdieu's concepts have been criticised because they suggest that capital and habitus are determined by educational structures, that individuals have little agency in this context and must adapt to controlling institutional cultures and processes. Hence, it is important to clarify, as Reay (2004) suggests, that this study adopts 'habitus' as a complex and 'multi-layered concept, with more general notions of habitus at the level of society and more complex, differentiated notions at the level of the individual (Reay, 2004, p434)'. In this article, 
international undergraduates are therefore understood as individuals with increasing agency who are empowered to contribute to their own development and success.

\section{Research aims and objectives}

Building on the earlier work described above (Thomas, 2002: Bourdieu and Passeron, 1977; Briggs et al., 2012; Authors, 2012; Pitman and Vidovitch, 2013; Authors, 2015) this research addressed a gap in the literature relating to the transition experiences of international undergraduate students who have attended an IFY at a pathway college. This study aimed to identify ways in which: 1. international undergraduates' experiences are influenced by both university and pathway college pedagogy and support practices; and 2. experiences vary among international undergraduates who have, and have not, completed an IFY in different UK universities and disciplinary contexts. Our findings help to identify effective practices and ways to address challenges when working with international students.

\section{Methodology}

\section{Research approach}

A sequential mixed-methods approach was adopted (Tashakkori and Teddlie, 2010) incorporating qualitative in-depth interviews that informed and were followed by a survey circulated across 4 UK universities (2 pre and 2 post-1992 universities). Interview and survey guidelines were also informed by a previous mixed-methods pilot study exploring the experiences of first year international students at one post-1992 university (Authors, 2015). In the new study, survey data helped to establish associations between variables on a broad scale. In-depth interviews provided insights into complex factors associated with 
varied and culturally inflected experiences of international undergraduates (Legard et al., 2003; Lewis, 2003). This research was ethically approved and data remains strictly confidential according to the Data Protection Act (1998). All participants were given information sheets, provided written consent prior to taking part in interviews and were free to withdraw from the research at any time. Participants' identities are anonymized in this article and all other written and spoken dissemination relating to this study.

\section{In depth interview participants, data collection and analysis}

In October 2015, adopting a purposive sampling strategy, our research team emailed first year international undergraduates who were studying Science, Business, Engineering and Arts disciplines on modules where previous IFY students had enrolled inviting them to participate in in-depth interviews. In 2015/16, we conducted 24 in-depth face-to-face interviews, including one paired interview, with first year international students across 1 pre and 2 post 1992 universities. These included 11 interviews in Business, 5 in Science, 3 in Engineering and 5 in Arts. Of the 25 participants, 19 attended an IFY and 6 did not. 22 participants were studying at post-1992 universities and 3 at a pre-1992 university. Interviews were digitally recorded and then transcribed. Data was qualitatively analyzed adopting cross-sectional content analysis methods, and NVivo facilitated data management. In this context, we explored students' varied experiences across disciplines, universities and by comparing previous IFY and non-IFY participants.

\section{Survey sample, data collection and analysis}

In Semester 2, a survey via Bristol Online Survey (BOS) was circulated to all first year international students studying Business, Science, Engineering, and Arts disciplines where previous IFY students were enrolled at the 4 participating UK universities. Following 
repeated email invitations to participate in the survey, 109 responses were received including one response from a UK home student that we removed from the dataset, leaving 108 first year students in the sample. This included international students from three institutions, post1992 a (100, 92.6\%), pre-1992 a (6, 5.6\%) and pre-1992 b (2, 1.6\%). A limitation of the survey sample being mainly from one post-1992 institution is that the survey findings represent and describe that student population rather than that any of the other participating institutions. In the sample, $45.4 \%$ attended an IFY in an international pathway college and $54.6 \%$ did not attend an IFY. 34.3\% (37) were male and 65.7\% (71) female and the majority of students (64.8\%) were 18-20 years old, 30.5\% aged $21-24$ and $4.6 \% 25$ years or older. Most respondents (66.7\%) were from outside the EU in comparison to $33.3 \%$ of EU students. Table 1 describes the sample and of those who completed an IFY the majority studied for two or three terms at a pathway college prior to university.

Table 1: Sample by discipline of study and completion of IFY and Non-IFY SPSS software was used to statistically analyse the survey to compare and examine differences between groups including former IFY students and non-IFY international 
students. In the findings we have included survey results that are significant in relation to the key themes presented in this article.

\section{Research findings}

The research findings in this article are organised in relation to 4 key emergent themes. These are: the role of friendship in students' social transition; the role of working relationships with staff and peers in building student belonging; academic challenges, developing resilience and independence in academic transition; and finally, the influence of the International Foundation Year: student development of institutional habitus, linguistic and academic capital. The following findings are supported by arguments made in earlier studies previously discussed in this article. These relate to undergraduates' loss of identity when changing institutions, and their development of cultural, social, academic and linguistic capital and institutional habitus over time related to a growing sense of belonging, engagement, confidence, resilience, learner identity and success (Scanlon et al., 2007; Leese, 2010; Gale and Parker, 2014).

\section{The role of friendship in students' social transition}

In this research, most interview participants across disciplines and universities described the importance of friends when starting a degree and settling into living in the UK. Students' social integration was strengthened by making new friends when starting their degrees. Earlier research similarly found that supportive relationships are important in students developing cultural and social capital, and a sense of belonging to the course and university, linked to institutional habitus (Thomas, 2002; Wilcox et al., 2005; Leese, 2010). For instance, Wilcox et al. found that friends can help support first year students, who feel isolated while 
adjusting to a new life at university (2005). Hence, emotional support can be significant in students' successful first year transition (Zepke and Leach, 2005; Trotter and Roberts, 2006).

We often stay until the building closes, which is at nine and sometimes eleven. It's interesting... you stay with friends, and not only work but have some fun, for example we listened to music while we were drawing or doing our projects.

(IFY Business P3)

PASS (Peer Assisted Study Support) sessions or student mentors, and orientation activities (a means to meet new friends and understand academic expectations) were also frequently described by participants as helping them to settle in when starting university. Participants who had attended an IFY described how friendships established during their time at the pathway college helped them to develop a sense of belonging when starting their degrees. Because of this, participants who had attended the IFY felt they had an advantage over those who did not attend an IFY.

I lived in shared accommodation at the time and that helped in the sense that I got to meet more people and that obviously opens you up, but also being at the pathway college helped. There was always information available at the reception. So if you need to know stuff or how to get around you could ask people... so that helped, and making different friends in the pathway college also.

(IFY Business P5)

The qualitative findings are also supported by the survey results in relation to the importance of friendship during transition. The survey data suggests that a majority of students made friends on their course (91.7\%). Overall 68.3\% said that friends supported their studies, $52.0 \%$ IFY students and $80.0 \%$ of non-IFY. This difference was statistically significant $\left(\mathrm{x}^{2}=\right.$ 
5.284, $\mathrm{df}=1, \mathrm{p}=.022)$ and therefore implies that non-IFY international students needed to rely more on support from friends in comparison to IFY students. For first year students who have lost a sense of belonging and identity during transition to $\mathrm{HE}$, the need to make friends is also described in earlier work as crucial in building social capital and institutional habitus, hence successfully navigating the first year transition (Scanlon et al., 2007).

However, not all participants in this research found making friends easy. A few participants described how UK students on their course formed cliques, which did not appear inclusive. For instance, a minority of participants described their lack of confidence in communicating in English and understanding the English accent, and because of this found it more difficult to make British friends. This finding reflects Leese's argument that lack of linguistic capital (an element of cultural capital) relates to difficulties in international student transition in English speaking HE contexts (Leese, 2010). Some participants in our research described how they did not want to get involved in the clubbing and restaurant culture that many UK students enjoyed and were less likely to make friends with UK students for this reason. These participants said they felt comfortable making friends with people from similar cultural, religious and linguistic backgrounds as they found it easier to relate to them.

In the university, English people have their groups, they're not really that open to talk to other people, and maybe I prefer to be with my other friends... international friends.

(Business IFY P5)

For IFY students, this finding also relates to the issue raised in the Background section regarding IFY students not mixing with UK students during the IFY and this being potentially unhelpful for students during transition to HE (McNorton and Cadinot, 2012). As Thomas (2015) and Leese (2010) argue, such challenges may be interpreted as students' 
perceived lack of identification with the privileged student identity and the need to develop capital and institutional habitus (Thomas, 2015; Leese, 2010).

\section{Strong working relationships with staff and peers at university building student belonging}

Interview participants often described ways in which developing good working relationships with academic staff and peers helped them to develop a sense of belonging. Aspects included: academic staff encouragement and friendliness, flexible spoken and online communication with academic staff including time to ask/answer questions, constructive feedback, lecture material including slides and podcasts being posted online in and outside formal teaching.

In Hong Kong we care about the different level of student and teacher, but here they are like friends, so like when you talk to your lecturers they are friendly to you... so you don't feel nervous, you can ask them anything, and they will answer you.

(IFY Arts P2)

Leese (2010), Thomas (2002) and Scanlon et al. (2007) also argue that effective working relationships with academic staff are crucial to first year students developing social and cultural capital and hence institutional habitus. In addition, earlier studies found that positive working relationships with teaching staff support first year international students' transition when starting degrees for instance through: continued written and spoken communication, constructive feedback, encouragement and face-to-face tutorials (Gu et al. 2009; Ramachandran, 2011). Conversely, Scanlon et al. (2007) suggest that if staff appear inaccessible to students, it is difficult for students to develop social capital linked to institutional habitus. 
In most disciplines, many research participants said that they found practical learning that related to real-life and professional experiences engaging. For instance, group or team work were often described as part of the disciplinary and professional culture within students' academic field, which helped participants develop learner and professional identities leading to their greater academic engagement and success. Hence, conceptually, it may be argued that students develop social and academic capital through their experiences of group-work.

The good thing is that teachers make you feel that Architecture is teamwork. You can't work as an architect without people to support you and share ideas. That's the good thing, I think, about my course. You always find people to help you and you learn from them and they learn from you.

(IFY Arts P1)

This finding is supported by Wilcox et al. (2005) who describe how students' development of strong working relationships with peers is important in their developing confidence (linked to social capital) and belonging at university (related to institutional habitus).

\section{Academic challenges, resilience and independence in academic transition}

Across disciplines, most interview participants, including former IFY students, described academic challenges, particularly in Semester 1. Previous IFY interview participants often said they found the transition to studying in university very different to the pathway college. Transition difficulties they described often related to students' need to work more independently at university and manage their own time, and receiving less academic support in comparison to greater support at the pathway college. These participants also often referred to learning in small groups at pathway colleges, in comparison to much larger groups 
during lectures at university, and how it was easier to ask lecturers questions and interact at pathway colleges, whereas at university it was more difficult. This may be interpreted as a socio-cultural issue for students that relates to the different cultures of pathway colleges and universities, and is linked to students' needs to develop the necessary social, cultural and academic capital and hence institutional habitus during transition (Leese, 2010).

When we were just 13 in the pathway college the teacher was I think more helpful with the students because we were just a few; but now it's a huge room and many students so the teacher gives us the materials and we have to do it by ourselves. In the pathway college the teacher is always there for you if you have a question, so I think it's very different.

(IFY Engineering P2)

In relation to this issue, a previous IFY participant was critical of the pathway college's approach of providing lots of support, which then made it more difficult for international students to adjust to the level of independence required when starting a degree.

I would say I don't really like the aspect of the college giving too much support because the student will now feel that when they get to the university they will get that kind of support; and then when they get there they figure out they don't get that support, so it will now be difficult for them to adjust.

(IFY Business P1)

Participants' awareness of their need to become independent learners shows their developing resilience and identity, which are also linked to their development of institutional habitus. While our findings show that IFYs help international students up to a certain point, arguably, there should be even greater connection between pathway-college and university learning practices in order to foster students' institutional habitus. 
Supporting these interview findings, the survey results also showed that a greater percentage of respondents found nearly all academic challenges (linked to academic and linguistic capital) difficult in Semester 1 in comparison to a smaller percentage in Semester 2. More non-IFY than IFY respondents found English Language difficult in Semesters 1 and 2; and more non-IFY than IFY respondents found exams, written coursework, group assignments and group work difficult in Semester 2. (Please see Table 2 below). This finding suggests that IFY students are likely to feel better prepared and more confident in these aspects that non-IFY students by Semester 2, which is also reflected by qualitative data. Hence, conceptually, previous IFY students are more likely to develop academic capital than non-IFY students by Semester 2.

Table 2. Aspects students found difficult in semester one and two (in percentage) by attending an IFY 


\section{The influence of the International Foundation Year: developing institutional habitus,}

\section{linguistic and academic capital}

By Semester 2, many previous IFY interview participants had become aware of their increased competence in English and academic writing, practical subject skills and knowledge of curriculum content. Thus, academically, the IFY had provided participants with solid building blocks of learning in relation to English language, subject knowledge and academic skills such as referencing and academic writing.

I think because of being in the pathway college, they teach us how to write essays and reports; and I think that was really helpful for my course because I have to write a lot of reports; and now I know how to write the structure and everything; so I find that's been really helpful. (IFY Business P5)

In relation to overcoming academic and linguistic challenges and developing resilience, previous IFY students' growing academic confidence during first year transition, linked to building linguistic and academic capital, is evident from our findings. As mentioned earlier in this article, linguistic and academic capital are related to the acquisition of knowledge (that previous IFY students had developed at the pathway college) (Leese, 2010). For instance, the following quote shows how participants benefited from having learnt the same basic curriculum content during the IFY that they were currently studying during their degrees; and how they perceived this to contribute to their confidence and success linked to academic capital.

It was very helpful because having gone to the International College I knew some of what to expect. Even now, I'm still not comfortable, but I'm happy because having gone through the International College, I know a lot compared to other people who never went to the International College. 
(IFY Business P4)

It is important to consider whether students' increased confidence in terms of linguistic competence, subject knowledge and academic skills translates into academic success. In this respect, additional evidence from ... (2016) supports our findings that attending the IFY contributes to international undergraduates' academic success. The .... report shows that of previous IFY students ' $76 \% \ldots$ achieved a first, $2: 1$ or a $2: 2$ ' and that in 2016 'the percentage of first and 2:1 classifications was higher than the equivalent percentages of Direct Entry International Students' (2016, 2). Conceptually, as earlier studies argue, academic success is underpinned by the accumulation of linguistic and academic capital (Leese, 2010; Pitman and Vidovitch, 2013).

\section{Developing institutional habitus in changing times: the wider implications}

This article focuses on the mainly positive aspects of attending an IFY and starting university that helps international students to build cultural, social and academic capital and institutional habitus, linked to belonging and success (Thomas, 2002; Scanlon et al., 2007; Leese, 2010; Pitman and Vidovitch, 2013; Gale and Parker, 2014). However, it is important to consider that negotiating the first year transition is a complex struggle for many first year international undergraduates, including those who have attended the IFY. One element of this struggle highlighted is the difficulty that some students describe in interacting with British students and adjusting to British language and culture. Hence, for these students it is challenging to develop cultural and social capital. In our research, some participants described how they felt excluded by home students. This sense of exclusion is also reflected by another recent study into the experiences of international students where: 'a key concern shared by many participants was the difficulties they encountered in establishing a relationship with British 
Culture, which led to feelings of alienation' (Newsome and Cooper, 2016, 205). It may be argued that there is a greater need for and focus on internationalisation in our universities that help promote social integration between home and international students. Moreover, it may be claimed that $\mathrm{HE}$ academic skills training and pedagogic practices are often presented in a politically and socially neutral way, which may clash with international students' previous educational experiences and practices (Kingston and Forland, 2008). Hence there may be further room for internationalisation in the IFY and university curricula.

For international students, a sense of not feeling welcome, and their difficulty in developing a sense of belonging and student identity and hence institutional habitus may be compounded by the wider socio-political context of cultural division currently taking place in the UK and internationally. An increased challenge for some students in developing a sense of belonging, identity and habitus may in turn detrimentally affect their academic confidence and success, linked to academic capital. For instance, if UK changes in immigration laws restrict international students' freedom to study and work in the UK, this may increase their sense of not feeling welcome. These debates might lead us to conclude that it is more challenging now for some international students to develop a strong sense of identity, belonging and institutional habitus in UK higher education in the current socio-political climate. On the other hand, some students may not connect political and media debates on immigration to their experiences of UK HE. However, universities need to continue to encourage internationalisation, inclusivity and diversity among their students, which enables the enculturation of institutional habitus and the acquisition of capital. In turn this will benefit the students themselves and wider society.

In order to enhance international students' opportunities to develop belonging and identity, linked to institutional habitus, and confidence and success, partner international colleges and universities share a joint responsibility to enhance existing good practice in 
learning, teaching and support. Firstly, connections between universities and pathway colleges could be strengthened in order to facilitate student transition. For instance, universities and partner colleges could hold annual meetings to discuss procedures, such as, online marking, virtual learning environment/internet use, deadlines, and rules and regulations. This would ensure that both partners share good practice and provide students with similar academic expectations and criteria. Pathway colleges could prepare international students more effectively to become independent learners and to manage time and workload when they start university, for instance through a gradual lessening of support throughout the IFY. Finally, and most importantly, universities and international colleges could develop international and home student integration with a greater overarching focus on internationalisation, for instance, during orientation, during extended induction activities' and through shared module delivery.

\section{Conclusion}

In conclusion, this research clarifies that many first year international undergraduates develop resilience, belonging, a strong sense of student identity, social and academic confidence and engagement linked to success when they experience: encouraging social support networks; strong working relationships with staff and peers; and motivating and collaborative learning, teaching and support during the first year transition in HE. Moreover, the findings show that international students are better prepared for the first year of their degrees when they have previously attended an IFY at a pathway college. However, all international students can face considerable challenges during transition, which can be difficult to overcome. Again, this is related to the idea that developing institutional habitus relates to the evolving student identity, which develops over time. 
In summary, it has been shown that previous IFY participants experienced similar challenges to other international students when starting their degrees, but struggled particularly in relation to adjusting to independent study, larger class sizes and decreased communication with academic staff, as described earlier in this article. Some, but not all, international students, described a need to adjust to new experiences of UK HE learning, to become independent learners, and to reach the required HE level in discipline-specific academic writing. Again, international students are not alone in these challenges, as UK students also face them (Authors, 2012). This highlights ways in which attending an IFY helps to enhance international students' confidence (linked to academic, cultural and social capital) to cope with these issues, particularly as the first year progresses.

It seems possible that a significant transition challenge is faced by all students when starting HE, including UK and international students, that is related to their social and academic integration with other students. It is now crucial for UK and other international universities and partner pathway colleges to work together to enhance existing good practice in learning teaching and support as described above; and within this context, to help counteract divisions between students from different ethnic and national backgrounds. Both partners can achieve this by encouraging student integration in the wider context of internationalisation and social justice, supporting all students to become global citizens in the future.

Word count: 6850

\section{Bibliography}

Andrade, M.S. 2006. "International students in English-speaking universities: Adjustment factors.” Journal of Research in International Education 5 (2): 131-154. 
Atkinson, W., 2011. From sociological fictions to social fictions: Some Bourdieusian reflections on the concepts of 'institutional habitus' and 'family habitus'. British Journal of Sociology of Education, 32(3), 331-347

Back, L., S. Sinha, and C. Bryan. 2012. "New hierarchies of belonging”, European Journal of Cultural Studies 15 (2): 139-154.

Bartram, B. 2008. "Supporting international students in higher education: constructions, cultures and clashes." Teaching in Higher Education. 13(6): 657-668. DOI:

$10.1080 / 13562510802452384$

Bourdieu, P. and J.C. Passeron. 1977. Reproduction in Education, Society and Culture. London and Beverley Hills: Sage Publications.

Bourdieu, P. 1988. Homo Academicus. Cambridge: Polity Press.

Bourdieu, P. 2002. "The forms of capital". In Readings in economic sociology, edited by N. Biggart. 280-291. Oxford: Blackwell.

Briggs, A.R.J., J. Clark and I. Hall. 2012. "Building bridges: understanding student transition to university." Quality in Higher Education. 18 (1): 3-21.

British Future and Universities UK. 2014. International students and the UK immigration debate, London: Universities UK Report, 2014.

Gale, T. and S. Parker. 2014. "Navigating Change: a typology of student transition in higher education." Studies in Higher Education. 39 (5):734-753.

Green, E. (2013). Research in the New Christian Academies, Perspectives from Bourdieu. Social Theory and Education Research. London: Routledge.

Griffiths, S.D, D. Winstanley and Y. Gabriel. 2005. "Learning Shock: The Trauma of Return to Formal Learning." Management Learning. 36 (3): 275-297.

Gu, Q., M. Schweisfurth and C. Day. 2009. "Learning and growing in a 'foreign; context: intercultural experiences of International students." Compare: A Journal of Comparative and International Education. 40 (1): 7-23.

Higher Education Academy (HEA). 2008. The first-year experience of higher education in the UK - Final Report. York: Higher Education Academy

Hurst, E., 2015. 'The thing that kill us': student perspectives on language support in a South African university. Teaching in Higher Education, 20(1), 78-91.

Jones, J. and S. Fleischer. 2012. "Staying on course: factors affecting first year International students' decisions to persist or withdraw from degrees in a post-1992 UK university."

Practice and Evidence of Scholarship of Teaching and Learning in Higher Education. 7 (1): 21-46.

Jones, J., S. Fleischer and A. McNair. 2015. "The International Foundation Year and Student Transition." Paper presented at the UKCISA annual conference, University of Sussex, Brighton, July 1-3.

Jones, J., S. Fleischer, S., A. McNair and R. Masika. 2017. "Exploring first year international undergraduates' experiences in four disciplines: influences of university and international 
partner college pedagogy and support practices." In Grants Scheme 2015-16: Research into the international student experience in the UK, United Kingdom Council for International Student Affairs (UKCISA) Combined Report

KAPLAN (KIC). 2013. University of Brighton International College web pages. Accessed April 12015.

http://www.kic.org.uk/brighton

KAPLAN. (KIC). 2016. University Performance Data of Pathway College Students: IFY Students and their Performance at University Undergraduate (UG) level

Kingston, E and H. Forland. 2008. "Bridging the Gap in Expectations Between International Students and Academic Staff." Journal of Studies in International Education. 12(2): 204-221.

Lee, J. 2010. "International students' experiences and attitudes to a US host institution: Selfreports and future recommendations." Journal of Research in International Education 9 (1) 66-84.

Leech S., Marshall C.A., Wren G. 2016. Understanding Foundation Year Provision. In: Marshall C., Nolan S., Newton D. (eds) Widening Participation, Higher Education and NonTraditional Students. Palgrave Macmillan, London, 19-40

Leese, M., 2010. Bridging the gap: supporting student transitions into higher education. Journal of further and Higher Education, 34(2), 239-251.

Legard, R., J. Keegan, J. and K. Ward. 2003. 'In depth Interviews' in J. Ritchie and J. Lewis (ed) Qualitative Research Practice, SAGE, London, 2003

Lewis, J. 2003. "Design Issues.” In Qualitative Research Practice, edited by J. Ritchie and J. Lewis. London: SAGE.

Li, G., W. Chen and J. L. Duanmu. 2010. "Determinants of International Students' Academic Performance." Journal of Studies in International Education. 14(1): 389-405.

Masika, R. and J. Jones. 2016. "Building student belonging and engagement: insights into higher education students' experiences of participating and learning together." Teaching in Higher Education. 21 (2): 138-150. DOI: 10.1080/13562517.2015.1122585

Matthews, D. 2014. Paths to Profit. In Times Higher Education March $20^{\text {th }} 2014$ https://www.timeshighereducation.com/features/pathways-to-profit/2012075.article [last accessed 15 May 2018]

McNorton, H. and S. Cadinot. 2012. "Enhancing the International Foundation Programme student experience: staying ahead of the game." InForm. 9 (2012): 5-8.

Morgan, J. 2016. "Indian student numbers continue to fall at UK universities", Times Higher Education, January 14.

https://www.timeshighereducation.com/news/indian-student 
Morris, M., C. Murray, and S. Murphy. 2016. "Destination education: Reforming migration policy on international students to grow the UK's vital education exports." The Independent, September 6.

https://www.ippr.org/publications/destination-education

Newsome, L.K. and P. Cooper. 2016. "International Students' Cultural and Social Experiences in a British University: 'Such a hard life (it) is here'." Journal of International Students. 6 (1): 195-215.

Pitman, T. and L. Vidovitch. 2013. "Converting RPL into academic capital: lessons from Australian universities." International Journal of Lifelong Education. 32 (4): 501-517.

Quan, R., J. Smailes and W. Fraser. 2013. "The transition experiences of direct entrants from overseas higher education partners into UK universities." Teaching in Higher Education. 18 (4): 414-426. DOI: 10.1080/13562517.2012.752729

Ramachandran, N. T. (2011). "Enhancing international students' experiences: An imperative agenda for universities in the UK." Journal of Research in International Education. 10(2): 201-220.

Reay, D., Ball, S. and David, M., 2002. 'It's taking me a long time but I'll get there in the end': mature students on access courses and higher education choice. British educational research journal, 28(1), pp.5-19.

Reay, D. 2004. 'It's all becoming a habitus': Beyond the habitual use of habitus in educational research. British Journal of Sociology of Education 25, no. 4: 431-44.

Scanlon, L, L. Rowling and Z. Weber. 2007. "You don't have to like an identity...you are just lost in a crowd: Forming a Student Identity in the First-year Transition to University." Journal of Youth Studies. 10 (2): 223-24.

Tashakkori, A. and C. Teddlie. 2010. "Putting the Human Back in "Human Research Methodology": The Researcher in Mixed Methods Research." Journal of Mixed Methods Research. 4(4): 271-277.

Thomas, L. 2002. "Student retention in higher education: the role of institutional habitus." Journal of Education Policy. 17(4): 423-442.

Thomas, L. 2012. Building student engagement and belonging in higher education at a time of change: final report from the What Works? Student Retention and Success programme. Higher Education Academy (HEA)

Thomas, K. 2015. Rethinking belonging through Bourdieu, diaspora and the spatial. Widening Participation and Lifelong Learning, 17(1), pp.37-49

Tinto, V. 2003. "Learning better together: The impact of learning communities on student success." Higher Education Monograph Series. 2003(1): 1-8. Higher Education Program, School of Education, Syracuse University. 
Travis, A. and S. Weale. 2016. "Amber Rudd announces crackdown on overseas students and work visas." The Guardian, October 4

https://www.theguardian.com/uk-news/2016/oct/04/

Trotter, E. and C.A. Roberts. 2006. "Enhancing the early student experience." Higher Education Research and Development, 25(4): 371-386.

United Kingdom Government. 1998. "The Data Protection Act.” HMSO.

http:/www.legislation.gov.uk/ukpga/1998/29/pdfs/ukpga 19980029 en.pdf

University of Brighton International College (2018), Unpublished Report

Wenger, E. 2009. “A Theory of Learning.” In Contemporary Theories of Learning: Learning Theorists...In Their Own Words edited by K. Illeris, Chapter 15. Abingdon and New York: Routledge.

Wilcox, P, S. Winn and M. Fyvie-Gauld. 2005. "It was nothing to do with the university, it was just the people': the role of social support in the first-year experience of higher education." Studies in Higher Education. 30(6): 707-722.

Zepke, N. and L. Leach. 2005. "Integration and adaptation: Approaches to the student retention and achievement puzzle." Active Learning in Higher Education. 6 (1): 46-50. 
Table 1: Sample by discipline of study and completion of IFY and Non-IFY

\begin{tabular}{llll}
\hline Discipline of study & IFY & Non-IFY & Total \\
\hline Arts & 12 & 22 & $34(31.5 \%)$ \\
Business & 11 & 19 & $30(27.8 \%)$ \\
Environment, Engineering and & 11 & 11 & $22(20.4 \%)$ \\
Computing & & & \\
Science (including Pharmacy) & 15 & 7 & $22(20.4 \%)$ \\
TOTAL & $\mathbf{4 9 ( 4 5 . 4 \% )}$ & $\mathbf{5 9 ( 5 4 . 6 \% )}$ & $\mathbf{1 0 8 ( 1 0 0 \% )}$ \\
\hline
\end{tabular}

Table 2. Aspects students found difficult in semester one and two (in percentage) by attending an IFY

\begin{tabular}{lllllll}
\hline Found difficult & \multicolumn{2}{c}{ IFY } & \multicolumn{2}{c}{ Non IFY } & \multicolumn{2}{c}{ All } \\
\hline & sem1 & sem2 & sem1 & sem2 & sem1 & sem2 \\
\hline Workload & 38.8 & 44.9 & 40.7 & 44.1 & 39.8 & 44.4 \\
\hline Meeting deadlines & 55.1 & 34.7 & 40.7 & 42.4 & 47.2 & 38.9 \\
\hline English language & 28.6 & 16.3 & 33.9 & 25.4 & 31.5 & 21.3 \\
\hline Exams & 38.8 & 24.4 & 23.7 & 35.6 & 30.6 & 30.6 \\
\hline Written coursework & 38.8 & 34.7 & 40.7 & 42.4 & 39.8 & 38.9 \\
\hline Giving presentations & 38.8 & 28.6 & 39.0 & 27.1 & 38.9 & 27.8 \\
\hline Group assignments & 38.8 & 22.4 & 25.4 & 32.2 & 31.5 & 27.8 \\
\hline Group work & 38.8 & 18.4 & 25.4 & 30.5 & 31.5 & 25.0 \\
\hline Understanding lectures & 34.7 & 14.3 & 28.8 & 20.3 & 31.5 & 17.6 \\
\hline Seminars & 30.6 & 10.2 & 22.0 & 20.3 & 25.9 & 15.7 \\
\hline Grades and feedback & 30.6 & 20.4 & 28.8 & 22.0 & 29.6 & 21.3 \\
\hline Making friends & 32.7 & 20.4 & 32.2 & 23.7 & 32.4 & 22.2 \\
\hline Family & 26.5 & 16.3 & 22.0 & 23.7 & 24.1 & 20.4 \\
\hline Money & 26.5 & 24.5 & 37.3 & 35.6 & 32.4 & 30.6 \\
\hline Accommodation & 24.5 & 24.5 & 25.4 & 25.4 & 25.0 & 25.0 \\
\hline Travel & 14.3 & 14.3 & 13.6 & 16.9 & 13.9 & 15.7 \\
\hline Understanding feedback & 14.3 & 16.3 & 15.3 & 22.0 & 14.8 & 19.4 \\
\hline Understanding university & 18.4 & 14.3 & 13.6 & 16.9 & 15.7 & 15.7 \\
rules & & & & & & \\
\hline Communication with & 28.6 & 28.6 & 20.3 & 25.4 & 24.1 & 26.9 \\
lecturers & & & & & & \\
\hline Reading & 26.5 & 20.4 & 23.7 & 25.4 & 25.0 & 23.1 \\
\hline n & $\mathbf{4 9}$ & $\mathbf{4 9}$ & $\mathbf{5 9}$ & $\mathbf{5 9}$ & $\mathbf{1 0 8}$ & $\mathbf{1 0 8}$ \\
\hline
\end{tabular}

